\title{
CD20 Expressing Cell Measurement
}

National Cancer Institute

\section{Source}

National Cancer Institute. CD20 Expressing Cell Measurement. NCI Thesaurus. Code C103368.

A count of the CD20 expressing cells per unit of a biological specimen. 